SHORT COMMUNICATION

\title{
YEAR-LONG CLENBUTEROL TREATMENT OF MICE INCREASES MASS, BUT NOT SPECIFIC FORCE OR NORMALIZED POWER, OF SKELETAL MUSCLES
}

\author{
Gordon S Lynch, Richard T Hinkle and John A Faulkner \\ Institute of Gerontology and Departments of Physiology and Biomedical Engineering, The University of \\ Michigan, Ann Arbor, Michigan, USA
}

\section{SUMMARY}

1. Clenbuterol has been proposed for the treatment of muscle wasting disorders, but its long-term effects on skeletal muscle function have not been tested rigorously. We tested the hypothesis that year-long treatment of young (6 months) mice with clenbuterol would increase skeletal muscle mass and in vitro measurements of specific force $\left(\mathbf{P}_{\mathbf{0}}\right)$ and power output.

2. Male mice (C57BL/10ScSn) were divided into treated $(n=6)$ or untreated $(n=8)$ groups. Treated mice received clenbuterol (1.5-2 mg/kg per day) in their drinking water for 52 weeks, following a staggered 3 day on/3 day off schedule to attenuate the response to clenbuterol.

3. Clenbuterol treatment increased the absolute mass of each muscle tested: the heart by $28 \%$, extensor digitorum longus (EDL) by $16 \%$, soleus by $22 \%$ and tibialis anterior by $17 \%$. For treated compared with untreated mice, absolute $P_{0}(\mathrm{mN})$ was greater in soleus muscles but not different in EDL muscles. Absolute power output ( $\mathrm{mW}$ ) of the EDL and soleus muscles was not different and no differences were observed for the specific $P_{0}\left(\mathrm{kN} / \mathrm{m}^{2}\right)$ or normalized power output (W/kg) of EDL muscles, soleus muscles or diaphragm muscle strips.

4. We conclude that, following year-long treatment of mice with clenbuterol, the mass of the heart and both fast and slow skeletal muscles is increased, but the lack of any change in normalized $\mathbf{P}_{0}$ or power output indicates that clenbuterol has little therapeutic effect on the functional properties of skeletal muscle.

Key words: $\boldsymbol{\beta}_{\mathbf{2}}$-adrenoceptor agonists, clenbuterol, contractile properties, force, power, skeletal muscle.

\section{INTRODUCTION}

Treatment with the $\beta_{2}$-adrenoceptor agonist clenbuterol produces significant increases in muscle mass and the muscle mass-body mass ratio (relative mass) in a number of different species. ${ }^{1}$ Consequently,

Correspondence: Dr Gordon S Lynch, Department of Physiology, The University of Melbourne, Parkville, Victoria 3052, Australia. Email: <g.lynch@physiology.unimelb.edu.au>

Received 11 May 1998; revision 3 August 1998; accepted 24 September 1998. clenbuterol has been proposed as a treatment to offset muscle atrophy associated with such conditions as ageing, ${ }^{2}$ denervation ${ }^{3-5}$ and immobilization or muscle unloading. ${ }^{6}$ The mechanism by which clenbuterol produces the hypertrophy of skeletal muscle is unclear, but increased protein synthesis, decreased protein degradation or a combination of the two have been proposed. ${ }^{7,8}$

Based on its anabolic properties, clenbuterol treatment has been recommended for humans suffering from muscle wasting diseases, such as muscular dystrophy, ${ }^{9,10}$ even though the long-term effects have not been established. In particular, muscle hypertrophy in the absence of any improvement in muscle function would be of only cosmetic significance, yet the impact of long-term clenbuterol treatment on the maximum force or power of skeletal muscles ${ }^{11}$ of either control or impaired skeletal muscles has received only limited attention. ${ }^{12}$ The purpose of the present study was to investigate the effects of year-long treatment with clenbuterol on the structure and function of skeletal muscles of mice. We tested the hypothesis that 52 weeks treatment of mice with clenbuterol would increase absolute and relative masses of heart and skeletal muscles, increase the absolute maximum force and power output of fast extensor digitorum longus (EDL) and slow soleus muscles and increase the specific maximum force production and normalized maximum power output of EDL muscles, soleus muscles and strips of diaphragm (DPM) muscles.

\section{METHODS}

\section{Animal groups and drug administration}

Young adult (6-month-old) male specific pathogen-free (SPF) C57BL/10ScSn mice were obtained from Jackson Laboratories (Bar Harbor, ME, USA) and housed in barrier-protected facilities of the Unit for Laboratory Animal Medicine at The University of Michigan. Mice were provided with standard laboratory chow and water ad libitum. All experiments were conducted in accordance with the guidelines outlined by the National Institutes of Health. ${ }^{13}$ Mice were separated into either treated or untreated groups and were housed in pairs or three to a cage. Long-term daily treatment with clenbuterol produces less hypertrophy than a staggered schedule of administration. ${ }^{14-16}$ Consequently, treated mice were given clenbuterol (Sigma Chemical Co., St Louis, MO, USA; $1.5-2 \mathrm{mg} / \mathrm{kg}$ per day) in their drinking water, every day for the first week and then followed a staggered 3 day on $/ 3$ day off schedule for the remainder of the 52 week protocol. To attenuate the response to clenbuterol even further, treatment was suspended for 7 days every 6 weeks. The clenbuterol solution was prepared fresh each week to avoid oxidation. The working dose of clenbuterol (1.5-2 $\mathrm{mg} / \mathrm{kg}$ per day) was established based on measurements of daily water consumption of individually housed mice 
(approximately $400 \mathrm{~mL} / \mathrm{kg})^{15}$ and a concentration $(5 \mathrm{mg} / \mathrm{mL}$ ) that has been shown previously to produce a maximal effect of the $\beta_{2}$-adrenoceptor agonist on skeletal muscle. ${ }^{15-17}$ The efficacy of clenbuterol administration via the drinking water has been well established. ${ }^{8}$ In our hands, the life span of C57BL/10ScSn mice housed under SPF conditions exceeds 28 months of age. Therefore, by the end of the 12 month clenbuterol treatment period, the mice would be considered to be older adult but not aged animals. Generally, age-related changes in structure-function relationships of skeletal muscles from these mice are not apparent until after 24 months of age. ${ }^{18}$

\section{Measurement of contractile properties}

Two days after the last treatment period, mice were anaesthetized with sodium pentobarbitone $(70 \mathrm{mg} / \mathrm{kg}$, i.p.), with supplemental doses administered as necessary to maintain adequate anaesthesia such that no response to tactile stimuli was observed. The fast EDL and slow soleus muscles from the left hindlimb were carefully excised tendon-to-tendon. In addition, the contractile properties of DPM muscle strips were investigated using techniques described previously. ${ }^{18} \mathrm{~A}$ silk suture was tied to each tendon of the isolated muscles, which were placed into a Plexiglass chamber filled with Ringer solution (containing (in mmol/L): $\mathrm{NaCl} 137 ; \mathrm{NaHCO}_{3} 24$; glucose $11 ; \mathrm{KCl}$ 5; $\mathrm{CaCl}_{2} 2 ; \mathrm{MgSO}_{4} 1 ; \mathrm{NaH}_{2} \mathrm{PO}_{4} 1$; tubocurarine chloride 0.025), $\mathrm{pH}$ 7.4, oxygenated with $95 \% \mathrm{O}_{2}$ and $5 \% \mathrm{CO}_{2}$ and maintained at $25^{\circ} \mathrm{C}$. Muscles were aligned horizontally between a servomotor lever arm (model $300 \mathrm{H}$; Cambridge Technology Inc., Watertown, MA, USA) and the stainless steel hook of a force transducer (model BG-50; Kulite Semiconductor Products Inc., Leonia, NJ, USA) and field stimulated by pulses transmitted between two platinum electrodes placed longitudinally either side of the muscle. Square wave pulses ( $0.2 \mathrm{~ms}$ duration) generated by a stimulator (model $\mathrm{S} 88$; Grass Instruments, Quincy, MA, USA) were amplified (model DC-300A Series II; Crown International Inc., Elkhart, IN, USA) to increase and sustain current intensity to a sufficient level to produce a maximum isometric tetanic contraction. ${ }^{18}$ Stimulation voltage and muscle length $\left(\mathrm{L}_{\mathrm{o}}\right)$ were adjusted to obtain maximum isometric twitch force. Optimum fibre length $\left(\mathrm{L}_{\mathrm{f}}\right)$ was determined by multiplying $\mathrm{L}_{\mathrm{o}}$ by previously determined fibre length to muscle length ratios of 0.44 for the EDL and 0.71 for the soleus muscle ${ }^{19}$ and 1.0 for the DPM. ${ }^{18}$ Maximum tetanic force production $\left(\mathrm{P}_{\mathrm{o}}\right)$ was determined from the plateau of the frequency-force relationship.

Power output was determined by isovelocity shortenings during maximum muscle activation. Initiation of the isovelocity shortening ramp and stimulation of the muscle occurred simultaneously. Stimulation was terminated at the end of the shortening ramp and the muscle was held isometric for $100 \mathrm{~ms}$, allowing it to relax before returning to resting length. Maximum power output was calculated as the product of average force and velocity of shortening. The average force generated during the shortening ramp was determined by integrating the area under the force curve and dividing by

Table 1 Selected morphometric characteristics of clenbuterol-treated and untreated control mice following 12 months clenbuterol administration

\begin{tabular}{llc}
\hline & $\begin{array}{l}\text { Control } \\
(n=6)\end{array}$ & $\begin{array}{l}\text { Treated } \\
(n=8)\end{array}$ \\
\hline Body mass (g) & $47 \pm 4$ & $47 \pm 2$ \\
Heart mass (g) & $0.14 \pm 0.01$ & $0.18 \pm 0.01^{*}$ \\
Heart mass/body mass & $0.33 \pm 0.02$ & $0.38 \pm 0.02$ \\
EDL mass (mg) & $12.7 \pm 0.6$ & $14.8 \pm 0.4^{*}$ \\
EDL mass/body mass & $0.27 \pm 0.02$ & $0.32 \pm 0.01$ \\
Soleus mass (mg) & $10.1 \pm 0.7$ & $12.3 \pm 0.6^{*}$ \\
Soleus mass/body mass & $0.22 \pm 0.01$ & $0.26 \pm 0.01^{*}$ \\
Tibialis anterior mass (mg) & $59.0 \pm 2.0$ & $68.9 \pm 1.4^{*}$ \\
Tibialis anterior mass/body mass & $1.33 \pm 0.08$ & $1.49 \pm 0.05^{*}$ \\
\hline
\end{tabular}

Values for heart mass/body mass are expressed as $(\mathrm{g} / \mathrm{g}) \times 100$; values for other muscle mass/body mass are expressed $(\mathrm{mg} / \mathrm{g}) \times 1000$.

${ }^{*} P<0.05$ for differences between muscles of treated and untreated mice. EDL, extensor digitorum longus. the elapsed time. The optimum shortening velocity $\left(\mathrm{V}_{\mathrm{opt}}\right)$ was defined as the velocity that resulted in maximum power. ${ }^{20}$ Specific force $\left(\mathrm{kN} / \mathrm{m}^{2}\right)$ values were normalized to mean total muscle fibre cross-sectional area (CSA), while power (W) was normalized by muscle mass (W/kg). After the contractile properties were measured, muscles were trimmed of their tendons and visible connective tissue and were weighed on an analytical balance (Mettler AE-50, Toledo, OH, USA). The total fibre CSA of each muscle was determined by dividing muscle mass by the product of $\mathrm{L}_{\mathrm{f}}$ and $1.06 \mathrm{mg} / \mathrm{mm}^{3}$ (the density of mammalian skeletal muscle). In addition, the heart and the tibialis anterior muscles were removed, blotted and weighed. The relative muscle mass of the heart and of each skeletal muscle was calculated as the muscle mass expressed as a proportion of the body mass.

\section{Statistical analysis}

Results are presented as the mean \pm SEM. Using NCSS software (Number Cruncher Statistical System 5.01, Kaysville, UT, USA), differences between treated and untreated groups were assessed using Student's $t$-test. Significance was set $a$ priori at $P<0.05$.

\section{RESULTS}

\section{Effect of clenbuterol treatment on muscle masses}

After 1 year clenbuterol treatment, the body masses of treated mice were not different from those of untreated mice (Table 1). In contrast, for treated compared with untreated mice, absolute muscle mass and relative muscle mass were greater for the heart (28 and $15 \%$, respectively) and for each of the three skeletal muscles (EDL: 12 and 18\%, respectively; soleus: 12 and $18 \%$, respectively; tibialis anterior 17 and $12 \%$, respectively).

\section{Effect of clenbuterol treatment on force and power output of skeletal muscles}

For EDL and soleus muscles from treated and untreated mice, absolute $\mathrm{P}_{\mathrm{o}}(\mathrm{mN})$ and absolute power output $(\mathrm{mW})$ were not different (Table 2). For the EDL muscles of treated mice, the $\mathrm{V}_{\text {opt }}$ was lower than that of untreated mice, but the power was unaffected because of a higher average force. For the soleus muscles and DPM strips, no differences were observed in $\mathrm{V}_{\text {opt }}$. The administration of clenbuterol had no effect on the specific $\mathrm{P}_{\mathrm{o}}\left(\mathrm{kN} / \mathrm{m}^{2}\right)$ or normalized power output (W/kg) of the EDL muscles, soleus muscles or DPM muscle strips (Table 2).

\section{DISCUSSION}

\section{Heart and skeletal muscle masses}

As reported previously by a number of investigators, ${ }^{1-3,7-9,12,14}$ the administration of clenbuterol increased absolute muscle mass and the muscle mass-body mass ratio of fast and slow skeletal muscles from 12 to $18 \%$, with the mass of the heart muscle increased to an even greater extent. The percentage increase in the soleus muscle was not different from increases reported after shorter periods ( 20 weeks) of administration. ${ }^{15}$ The percentage increase in the EDL muscle was greater in the present study (52 weeks of treatment) compared with the increase reported by Hayes and Williams ${ }^{15}$ following 20 weeks of administration, which suggests that the effectiveness of clenbuterol in increasing muscle mass continues for the duration of the treatment period. The changes in composition of the muscle fibre types are much more variable and do not appear to be of any functional significance. ${ }^{16,21-23}$ 
Table 2 Contractile properties of extensor digitorum longus and soleus muscles and diaphragm muscle strips from clenbuterol-treated and untreated control mice following 12 months clenbuterol administration

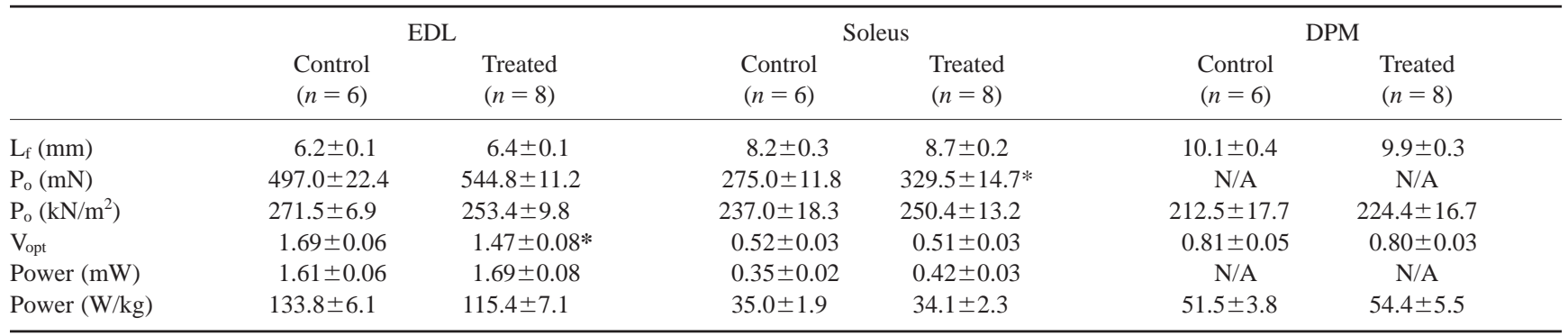

For diaphragm muscle strips (DPM), the width and thickness and, consequently, mass vary among animals at the discretion of the surgeon excising them. Hence, absolute forces and powers developed by DPM have no physiological meaning and comparisons can only be made after the forces and powers have been normalized for total fibre cross-sectional area $\left(\mathrm{kN} / \mathrm{m}^{2}\right)$ and mass $(\mathrm{W} / \mathrm{kg})$, respectively. ${ }^{18}$

$* P<0.05$ for differences between muscles of treated and untreated mice.

$\mathrm{L}_{\mathrm{f}}$, muscle fibre length; $\mathrm{P}_{\mathrm{o}}$, tetanic force; $\mathrm{V}_{\mathrm{opt}}$, optimum velocity for maximum power output; N/A, not applicable.

\section{Contractile properties}

Considerable controversy exists as to the effect of clenbuterol on the development of absolute and specific $\mathrm{P}_{\mathrm{o}}$. Short periods (14 days) of clenbuterol treatment did not alter the absolute or specific $\mathrm{P}_{\mathrm{o}}$ of rat medial gastrocnemius muscle ${ }^{24}$ or the gastrocnemiusplantaris-soleus muscle complex. ${ }^{23}$ Longer periods of administration (up to 20 weeks) also have not altered the absolute or specific $\mathrm{P}_{\mathrm{o}}$ of the EDL muscle from rats or mice. ${ }^{3,15}$ The effect of similar shorter periods (up to 20 weeks) of clenbuterol administration on the absolute or specific $\mathrm{P}_{\mathrm{o}}$ of the soleus muscle has produced conflicting results. ${ }^{3,15,16}$ Our observation of a small but significant increase in absolute $\mathrm{P}_{\mathrm{o}}$ of the soleus muscle following year-long clenbuterol treatment is consistent with the data of Dupont-Versteegden et al., ${ }^{12}$ who reported an increase in absolute $\mathrm{P}_{\mathrm{o}}$ of the EDL muscles obtained from control (C57BL/10SNJ) mice and those subjected to 1 year continuous treatment with clenbuterol ( $1.0-1.5 \mathrm{mg} / \mathrm{g}$ per day) in the drinking water. Similarly, our data are in good agreement with the conclusion of these investigators ${ }^{12}$ that clenbuterol produced no change in the specific $\mathrm{P}_{\mathrm{o}}$ of soleus muscles or DPM muscle strips. Based on our data and the supportive observations of other groups, we conclude that clenbuterol treatment, even of year-long duration, has only a minor effect on the absolute force of slow, but not fast, skeletal muscles and has no effect on the specific force production of fast or slow skeletal muscles.

One of the most important capabilities of skeletal muscles is to do work and generate power. ${ }^{11}$ The effect of clenbuterol on the power output of fast and slow skeletal muscles has not been reported previously. Assuming that the anabolic and lipolytic effects of clenbuterol $^{7,25}$ will also enhance performance, clenbuterol is frequently used by athletes, especially those involved in strength- and power-related sports. ${ }^{26}$ The year-long treatment with clenbuterol of young mice, with significant muscle hypertrophy but no evidence of any increase in normalized force or power of either fast or slow skeletal muscles, provides no support for such an assumption.

\section{CONCLUSIONS}

Because all physical activities require muscles to generate force and power, ${ }^{20,27}$ an increase in muscle mass in the absence of functional improvement is of no consequence. Despite several studies suggesting that clenbuterol has therapeutic potential for treating muscle wasting disorders, ${ }^{9,10}$ few investigators have studied the long-term effects of $\beta_{2}$-adrenoceptor agonist administration on skeletal muscle function. ${ }^{12}$ Year-long treatment with clenbuterol increased skeletal muscle mass, but did not alter either the specific $\mathrm{P}_{\mathrm{o}}$ or absolute or normalized power output of EDL, soleus or DPM muscles. The lack of improvement in contractile function following year-long administration of clenbuterol, despite the increases in muscle mass, indicates that clenbuterol has little long-term therapeutic potential for improving muscle contractility.

\section{ACKNOWLEDGEMENTS}

This work was supported by a National Institutes of Health grant AG-06157 (to JAF). GSL was supported by a CJ Martin Research Fellowship from the National Health and Medical Research Council of Australia.

\section{REFERENCES}

1. Kim YS, Sainz RD. $\beta$-Adrenergic agonists and hypertrophy of skeletal muscles. Life Sci. 1992; 50: 397-407.

2. Carter WJ, Dang AQ, Faas FA, Lynch ME. Effects of clenbuterol on skeletal muscle mass, body composition, and recovery from surgical stress in senescent rats. Metabolism 1991; 40: 855-60.

3. Agbenyega ET, Wareham AC. Effect of clenbuterol on normal and denervated muscle growth and contractility. Muscle Nerve 1990; 13: 199-203.

4. Maltin CA, Hay SM, Delday MI, Smith FG, Lobley GE, Reeds PJ. Clenbuterol, a beta-agonist, induces growth in innervated and denervated rat soleus muscle via apparently different mechanisms. Biosci. Rep. 1987; 7: 525-32.

5. Zeman RJ, Ludemann R, Etlinger JD. Clenbuterol, a $\beta_{2}$-agonist, retards atrophy in denervated muscles. Am. J. Physiol. 1987; 252: E152-5.

6. Delday MI, Maltin CA. Clenbuterol increases the expression of myogenin but not MyoD in immobilized rat muscles. Am. J. Physiol. 1997; 35: E941-4.

7. Choo JJ, Horan MA, Little RA, Rothwell NJ. Anabolic effects of clenbuterol on skeletal muscle are mediated by $\beta_{2}$-adrenoceptor activation. Am. J. Physiol. 1992; 26: E50-6.

8. Moore NG, Pegg GG, Sillence MN. Anabolic effects of the $\beta_{2}$-adrenoceptor agonist salmeterol are dependent on route of administration. Am. J. Physiol. 1994; 267: E475-84.

9. Maltin CA, Delday MI, Watson JS et al. Clenbuterol, a $\beta$-adrenoceptor agonist, increases relative muscle strength in orthopaedic patients. Clin. Sci. 1993; 84: 651-4. 
10. Zeman RJ, Zhang Y, Etlinger JD. Clenbuterol, a $\beta_{2}$-agonist, retards wasting and loss of contractility in irradiated dystrophic $m d x$ muscle. Am. J. Physiol. 1994; 267: C865-8.

11. Jones NL, McCartney N, McComas AJ. Human Muscle Power. Human Kinetics Publishers Inc., Champaign, IL. 1986.

12. Dupont-Versteegden EE, Katz MS, McCarter RJ. Beneficial versus adverse effects of long-term use of clenbuterol in $m d x$ mice. Muscle Nerve 1995; 18: 1447-59.

13. National Institutes of Health. Guide for the Care and Use of Laboratory Animals. Office of Science and Health Reports. Public Health Service Publication No. 86-23, Bethesda, MD. 1985.

14. Yang YT, McElligott MA. Multiple actions of $\beta_{2}$-adrenergic agonists on skeletal muscle and adipose tissue. Biochem. J. 1989; 261: 1-10.

15. Hayes A, Williams DA. Long-term clenbuterol administration alters the isometric contractile properties of skeletal muscle from normal and dystrophin-deficient $m d x$ mice. Clin. Exp. Pharm. Physiol. 1994; 21 : 757-65.

16. Zeman RJ, Ludemann R, Easton TG, Etlinger JD. Slow to fast alterations in skeletal muscle fibres caused by clenbuterol, a $\beta_{2}$-receptor agonist. Am. J. Physiol. 1988; 254: E726-32.

17. Lynch GS, Hayes A, Campbell SP, Williams DA. Effects of $\beta_{2}$-agonist administration and exercise on contractile activation of skeletal muscle fibers. J. Appl. Physiol. 1996; 81: 1610-18.

18. Lynch GS, Rafael JA, Hinkle RT et al. Contractile properties of diaphragm muscle segments from old $m d x$ and old transgenic $m d x$ mice. Am. J. Physiol. 1997; 272: C2063-8.
19. Brooks SV, Faulkner JA. Contractile properties of skeletal muscles from young, adult and aged mice. J. Physiol. 1988; 404: 71-82.

20. Brooks SV, Faulkner JA, McCubbery DA. Power outputs of slow and fast skeletal muscles of mice. J. App. Physiol. 1990; 68: $1282-5$.

21. Maltin CA, Delday MI, Reeds PJ. The effect of a growth promoting drug, clenbuterol, on fiber frequency and area in hind limb muscles from young male rats. Biosci. Rep. 1986; 6: 293-9.

22. Torgan CE, Etgen GJ, Kang HY, Ivy JL. Fiber type-specific effects of clenbuterol and exercise training on insulin-resistant muscle. J. Appl. Physiol. 1995; 79: 163-7.

23. Dodd SL, Powers SK, Vrabas I, Criswell D, Stetson S, Hussain R. Effects of clenbuterol on contractile and biochemical properties of skeletal muscle. Med. Sci. Sports Exer. 1996; 28: 669-76.

24. Murphy RJL, Béliveau L, Seburn KL, Gardiner PF. Clenbuterol has a greater influence on untrained than on previously trained skeletal muscle in rats. Eur. J. Appl. Physiol. 1996; 73: 304-10.

25. MacLennan PA, Edwards RHT. Effects of clenbuterol and propranolol on muscle mass. Evidence that clenbuterol stimulates muscle $\beta$-adrenoceptors to induce hypertrophy. Biochem. J. 1989; 264: 573-9.

26. Prather ID, Brown DE, North P, Wilson JR. Clenbuterol: A substitute for anabolic steroids. Med. Sci. Sports Exerc. 1995; 27: 1118-21.

27. Hill AV. The dimensions of animals and their muscular dynamics. Proc. R. Inst. Gt Br. 1950; 34: 450-71. 